\title{
ESTÁGIO VIRTUAL À DISTÂNCIA: Um estudo de caso para o ensino de engenharia de usabilidade
}

\author{
Renate de Oliveira Raabe * \\ Walter de Abreu Cybis **
}

\begin{abstract}
Resumo: Este artigo apresenta a proposta do "Estágio Virtual", como abordagem pedagógica para o ensino à distância em Engenharia de Usabilidade seguindo a teoria sócio-interacionista de Vygotsky. O "Estágio Virtual" foi desenvolvido com o objetivo de viabilizar um estágio fictício em uma empresa também fictícia, tendo como objetivo motivar, informar e principalmente capacitar, acadêmicos em engenharia de usabilidade, através de atividades práticas semelhantes àquelas realizadas em empresas do mercado de trabalho real. Relata também a aplicação desta proposta em um estudo de caso, bem como, as conclusões que dele se pode tirar. A análise do experimento demonstrou a validade da proposta e possibilitou a identificação de vantagens, problemas com suas respectivas causas e soluções.
\end{abstract}

Palavras-chave: Estágio Virtual à Distância; Educação à Distância; Engenharia de Usabilidade; SócioInteracionista.

\begin{abstract}
This paper presents "Virtual Treinee" proposal as an pedagogical approach for distance learning of Usability Engeneering based on social interaction Vygotsky theory. "Virtual Treinee" was developed to allow probationers to work in a virtual manner in a virtual enterprise whith the intention of motivating, informing and mainly capacitating students of Usability Engeneering through practical activities similar to those of real enteprises. This paper also presents the aplication of this proposal in a case-study and the respective conclusions of the experiment. The experiment analysis shown the viability of the proposal and allowed to identify advantages, problems and its respective solutions.
\end{abstract}

Key words: Virtual Treinee; Distance Learning; Usability Engeneering; Social Interaction Theory.

\section{INTRODUÇÃ̃O}

A importância da Engenharia de Usabilidade para formação de bacharéis em Sistemas de Informação vem aumentando nos últimos anos no Brasil. E-commerce, $e$ learning, e-governement, e-entertainement, entre outras $e$-application colocam cada vez mais os cidadãos dependentes da Internet e do emprego de computadores.

Como reflexo deste fato, um número crescente de empresas produtoras de sistemas interativos, estão despertando para a necessidade de investimentos em profissionais, nesta área, aptos em aprimorar a qualidade de produtos relativos ao quesito usabilidade de suas interfaces.

Por exemplo, no Workshop Design de Interface Centrado no Usuário ${ }^{1}$, foram relatadas diversas experiências de empresas brasileiras que investem em profissionais de usabilidade, tais como: Globo.com, Sirius Soluções Interativas, E-Bit e MPPSolution.

A demanda de trabalho na área está aumentando, porém, o ensino de engenharia de usabilidade nas universidades ainda encontra-se distante da prática das empresas. Normalmente, os planos de ensino são elaborados com objetivos apenas instrucionais distanciando a teoria da prática, ou seja, sem preocupação com a formação do

\footnotetext{
* Mestre pelo Programa de Pós-Graduação em Engenharia de Produção e Sistemas - UFSC. (renate@ eps.ufsc.br)

** Professor Dr. do Programa de Pós-Graduação em Engenharia de Produção e Sistemas e do Programa de PósGraduação em Ciência da Computação - UFSC. Coordenador do LabIUtil - Laboratório de Utilizabilidade CTC/INE/UFSC. (cybis@inf.ufsc.br)

${ }^{1}$ Workshop de Aplicação das Melhores Práticas em Projetos Web na América Latina realizado no CLIHC (Congresso Latino-Americano de Interação Humano Computador) deste ano.
} 
acadêmico para a aquisição de experiência profissional. Segundo Niskier (2000), diante da globalização do mercado econômico mundial, da alta competitividade e da estreita correlação entre educação e produtividade, torna-se notável a baixa qualificação de profissionais em tecnologia. Como consequiência desses problemas, passa então a ocorrer uma carência de profissionais qualificados em engenharia de usabilidade para atender a demanda do mercado de trabalho.

O ensino de engenharia de usabilidade ressente-se de oportunidades de estágios, que poderiam ser alternativas pedagógicas ao ensino acadêmico desta matéria. Por outro lado, mesmo na modalidade de estágio, os alunos correm o risco de aprender pouco, pois as boas oportunidades de aprendizado ocorrem quando boas empresas desenvolvem bons projetos de usabilidade. Muitas vezes, as atividades das quais participam os acadêmicos nas empresas não são as melhores para o desenvolvimento de suas competências. Às vezes, elas já podem ter ocorrido, ou em outras ainda vão ser executadas, talvez em cidades distantes. Em suma, as boas oportunidades de aprendizado ocorrem em determinados momentos e em determinados locais, nem sempre ao alcance dos alunos.

A Educação à Distância (EAD), via Internet, aparece como resposta às necessidades de flexibilização do local e do horário de estudo dos alunos, respeitando assim, o seu ritmo individual de aprendizagem. Por outro lado, a existência de ferramentas computacionais para suporte a autoria de cursos via Internet e a ampla documentação relativa a iniciativas de cursos à distância com as mais diversas abordagens pedagógicas representam uma oportunidade para professores. Porém, existem casos em que a EAD ainda tende a reproduzir o ensino tradicional havendo pouca formação em treinamento. Segundo Blikstein (apud Silva 2003), nestes casos, a educação continua a ser, mesmo na tela do computador on-line, a transmissão de conteúdos empacotados. Entretanto, a modalidade de EAD permite explorar diferentes abordagens pedagogias que não estejam baseadas simplesmente na informação, mas também em treinamento em atividades práticas em um contexto social e histórico (Vygotsky).

O "Estágio Virtual” proposto pode ser definido como uma simulação da função de engenharia de usabilidade em uma empresa fictícia, com departamentos, responsáveis, com clientes, contratos, atividades, normas e procedimentos também fictícios. Tudo orquestrado para proporcionar oportunidades de formação prática e teórica através de experiências sociais, sincronizadas com um semestre letivo. Esta é a proposta pedagógica tratada neste artigo.

Acredita-se que o "Estágio Virtual" via Internet seja uma forma de aumentar a qualidade do ensino-aprendizagem e de possibilitar uma melhor formação a acadêmicos em engenharia de usabilidade. Visa dar oportunidade para que os alunos vivenciem as situações práticas de convívio social comuns no dia a dia da empresa. Desta forma, tirase proveito dos benefícios provenientes da realização de um estágio e também das possibilidades inerentes ao estudo a distância. A definição de uma empresa fictícia permite que as demandas, projetos e clientes da empresa sejam ajustados às necessidades de aprendizagem dos alunos, proporcionando assim um estudo contextualizado e focalizado.

\section{ENGENHARIA DE USABILIDADE}

Segundo Mayhew (1999), a engenharia de usabilidade está definida como a disciplina que fornece métodos estruturados para a obtenção da usabilidade durante $o$ desenvolvimento de sistemas interativos. E, possui raízes em disciplinas como: a 
psicologia cognitiva, sociologia, ergonomia, semiótica, engenharia de software, entre outras.

É uma área que vem sendo bastante difundida nos últimos anos. O desenvolvimento de métodos e práticas de engenharia que assegurem uma interação computador-usuário com qualidade vêm alcançando grande importância, já que nos softwares atuais, o percentual de dedicação à interface com o usuário atualmente está em aproximadamente 50\% (Pádua, 2003).

Como consequiência a demanda do trabalho de engenheiros de usabilidade está crescendo. Assim, acredita-se na expansão da implantação de disciplinas de engenharia de usabilidade nos cursos de graduação em Sistemas de Informação das instituições de ensino.

\section{EAD VIA INTERNET}

A educação à distância baseada na internet é algo recente e, no início deste novo milênio, ninguém pode ainda se intitular um profundo conhecedor ou grande especialista no assunto. Porém, pode-se constatar que é um meio para a publicação do material de um curso, apresentação de tutoriais, aplicação de testes e comunicação com os estudantes (Lucena, 2000).

O mercado de trabalho está mudando e a necessidade de treinamento e educação aumenta na mesma medida. Diante dessa realidade a EAD mostra-se como uma das alternativas ao ensino convencional na medida em que permite uma estratégia de ensino centrada no estudo ativo e independente que, combinando técnicas variadas, dispensa ou reduz as situações presenciais de ensino e permite que o estudante eleja seu ritmo, tempo e local de estudo.

\section{AMBIENTE VIRTUAL DE APRENDIZAGEM - TELEDUC}

O TelEduc é classificado como um ambiente virtual de aprendizagem. Os AVA são abrangentes e não tratam apenas de ambientes cooperativos, mas de qualquer ambiente que permita a realização e gerência de um curso através da Internet (LIMA, 2002).

Segundo Vavassori e Raabe (2003), ambientes virtuais de aprendizagem (AVA) podem ser definidos como sistemas que agrupam um conjunto de recursos e ferramentas que permitem potencializar sua utilização em atividades de aprendizagem através da Internet em um curso à distância.

Estes ambientes virtuais favorecem a descentralização e a distribuição de informações relativas ao conhecimento humano e as ferramentas tecnológicas inseridas nestes ambientes movimentam a informação, bem como, facilitam o contato entre pessoas.(Fucks, 2000).

O TelEduc é um ambiente para a criação, participação e administração de cursos na Web. Foi concebido tendo como alvo o processo de formação de professores para o uso da Informática na Educação, baseado na metodologia de formação construcionista e contextualizada desenvolvida por pesquisadores do Nied (Núcleo de Informática Aplicada à Educação) da Unicamp (TELEDUC, 2003).

\section{ABORDAGEM SÓCIO-INTERACIONISTA DE VYGOTSKY}

A questão central de Lev Semenovich Vygotsky em sua abordagem é a aquisição de conhecimentos pela interação do sujeito com o meio. Ou seja, sua teoria 
compreende o desenvolvimento humano como um processo de interação entre sujeitosujeito e sujeito-meio de forma mediada.

Para este trabalho, as principais idéias da abordagem de Vygotsky consideradas foram: Mediação, Linguagem, Zona de Desenvolvimento Proximal (ZDP), Formação de Conceitos Cotidianos ou Espontâneos e Científicos, Cultura, bem como, Instrumentos e Signos (Rego, 1999).

É notória a importância que Vygotsky atribui ao papel da interação social no desenvolvimento do ser humano. A interação está inserida dentro do processo de mediação que ocorre por meio de instrumentos e signos.

Os instrumentos e signos estão presentes em ambientes de EAD na linguagem adotada para a comunicação, nos recursos gráficos e mnemônicos, utilizados para a interação, nos serviços de e-mail, de fórum, nas ferramentas de chat e em toda e qualquer ferramenta que exerça a função de mediação. Símbolos, signos e palavras constituem um meio de contato entre o ambiente computacional e os seus usuários (VICCARI e ANDRADE, 2003).

Como será apresentado a seguir, o "Estágio Virtual" tornou-se uma maneira de implementar a teoria sócio-interacionista de Vygotsky.

\section{PROPOSTA DE ESTÁGIO VIRTUAL}

A proposta do estágio virtual consiste da definição de uma empresa fictícia, denominada labiutil empresa virtual com estrutura, regulamentos e dinâmica estabelecida. Esta aborda também a estrutura do hiperdocumento construído para disponibilizar o material teórico aos alunos.

\subsection{Website para a Empresa Virtual Fictícia}

As definições para a empresa "LabIUtil Empresa Virtual" tiveram o objetivo de proporcionar a contextualização e integração dos alunos (futuros estagiários) com o seu cenário organizacional e funcional estruturado. A estrutura geral da empresa é definida principalmente através de um website composto por um organograma com departamentos funcionais e de projeto, por personagens (funcionários fictícios), por uma metodologia com formas de organização de trabalho e regulamentos, bem como, um plano de avaliação contendo a descrição de como os estagiários/alunos serão avaliados nas suas atuações durante as atividades. Este website foi construído com o propósito de proporcionar a familiarização do aluno com a empresa a estagiar. E este foi inserido no ambiente TelEduc.

\subsection{Programa Geral de Atividades}

A dinâmica do estágio virtual está definida no Programa Geral de Atividades, documento que está publicado no website da empresa no ambiente TelEduc. São previstas as seguintes atividades:Admissão e Formação de Grupos; Nivelamento nos fundamentos de Eng. Usabilidade; Análise de Requisitos de Usabilidade; Montagem de Guia de Recomendações; Projeto de Interface; Montagem de Lista de Verificação de Usabilidade e Avaliação de Usabilidade.

\subsection{Hiperdocumento}

4 V. 2 № 1, Março, 2004 
Foi implementado a partir da apostila LABIUTIL ${ }^{2}$ utilizada pelo co-autor deste artigo para seus cursos de Engenharia de Usabilidade, e também foi integrado ao ambiente TelEduc. Ele representa uma fonte para informações para pesquisas dos estagiários durante as atividades técnicas e de nivelamento. Foi dividido em 04 unidades: Usabilidade e Engenharia de Usabilidade; Fundamentos Teóricos da Engenharia de Usabilidade; O Ciclo da Engenharia da Usabilidade; Ferramentas para a Engenharia da Usabilidade.

\section{ESTUDO DE CASO}

O estudo de caso foi dimensionado para ser realizado durante um mês, no período de 21 de março a 28 de abril de 2003, abrangendo as duas primeiras atividades técnicas, além das preliminares de admissão. Neste período o "Estágio Virtual" substituiu a disciplina presencial. Este estudo foi realizado, com 35 alunos inscritos na disciplina de Engenharia de Usabilidade do $6^{\circ}$ período do curso de Sistemas de Informação da UFSC. Para tanto foi criado um curso para abrigar o estudo de caso com o "Estágio Virtual". Este curso foi integrado ao TelEduc por meio de suas ferramentas.

É importante mencionar que o TelEduc teve como papel principal proporcionar as interações entre alunos (estagiários), professor, tutor e os personagens (funcionários) da empresa por meio dos recursos tecnológicos necessários para o processo.

\subsection{Realização do Estudo de Caso}

No dia 21/03, realizou-se a primeira reunião presencial em sala de aula com os alunos, para apresentar a proposta do Estágio Virtual à Distância e dar início ao experimento. Durante a apresentação, foram explicadas as principais características do "Estágio Virtual", tais como: a ementa e o plano de ensino para o "Estágio Virtual", as funcionalidades do ambiente TelEduc, a estrutura do website da empresa fictícia e do hiperdocumento. Neste encontro fez-se uma tentativa de conscientização por parte dos alunos mostrando a eles a importância da adoção de uma postura colaborativa, profissional e responsável durante todo o processo.

No dia 25/03, iniciou-se o processo das inscrições dos 35 alunos no TelEduc através da ferramenta "Administração" e em 26/03, primeiro dia do estudo de caso, os alunos iniciaram o processo de interação com o ambiente realizando as atividades prérequisitos (Admissão e Formação de Grupos) para a Atividade 1.

A atividade pré-requisito (Plano de Admissão) tratava das "entrevistas virtuais" que os alunos tinham que fazer com o psicólogo para serem autorizados a fazer parte do quadro de estagiários da empresa. A outra atividade pré-requisito (formação dos grupos de trabalho), foi realizada antes da primeira atividade técnica ser agendada. Os fóruns de discussão para os grupos e com temas tais como: Dúvidas Gerais e Problemas de Usabilidade no Teleduc e no website da Empresa se apresentaram como maneira de canalizar as discussões que se iniciaram imediatamente e com bastante intensidade entre os alunos da disciplina, motivados pelo fato de estarem realizando uma formação em engenharia de usabilidade.

\footnotetext{
${ }^{2}$ Abordagem Ergonômica para IHC - Apostila de Curso. Laboratório de Utilizabilidade INE/UFSC, Florianópolis, Brasil, 2003.
} 
A Atividade 1 consistiu do primeiro curso de Nivelamento (formação) em engenharia de usabilidade e nas ciências/disciplinas que fundamentam suas práticas. Nesta primeira atividade os líderes, discutindo com os demais integrantes do grupo, realizaram a análise dos conteúdos e fizeram o planejamento da repartição das tarefas pela estrutura dos conteúdos. Após a reunião, os alunos (executores) iniciaram a realização das tarefas individuais estabelecidas durante as discussões. Por fim, os líderes das equipes realizaram a revisão e a integração das tarefas individuais. Esta atividade foi concluída somente no dia 09/04 devido a problemas com a ferramenta "Correio" para Grupos.

No dia 28/04 as notas do curso de nivelamento foram repassadas aos grupos através da ferramenta "Mural". Para o líder de equipe com melhor atuação foi dado um bônus de 0,5 ponto na média.

No dia 10/04 a segunda atividade foi iniciada. Consistiu da realização técnica da Especificação dos Requisitos de Usabilidade para o website HomeOpera de uma empresa cliente do LabIutil, a Neogrid. Esta empresa é uma empresa real para qual o LabIUtil presta serviços de avaliação de usabilidade. Trata-se de uma das poucas empresas no Brasil com um engenheiro de usabilidade formalmente instituído, o Sr. Vinicius Rodrigues Nunes, que manifestou interesse em participar da experiência do estágio virtual. Assim, o Sr. Vinicius desempenhou o único papel real do estudo de caso, o de engenheiro de usabilidade da Neogrid. Entretanto, o website HomeOpera era fictício. Para esta atividade foi escolhido um novo líder de equipe por grupo e os demais membros foram os executores.

Esta atividade foi organizada em duas etapas. Na primeira eles estudavam a estrutura da norma ISO 9241:11 e deviam produzir um questionário de análise a ser enviado ao Sr. Vinicius, o engenheiro de usabilidade da Neogrid. Antes porém, elas deveriam manter um contato com a Sra Virgínia Leite, Gerente do Dept. de Projetos do LabIUtil, Empresa Virtual, que devia aprovar o documento com a entrevista. Na segunda etapa da atividade, os alunos recebiam o questionário preenchido pelo Sr. Vinicius e elaboravam o documento de especificação de requisitos de usabilidade para o website HomeOpera.

Do dia 10 a 14/04 os alunos elaboraram um documento inicial com a estrutura das especificações do contexto de uso e das medidas de usabilidade a partir do documento "Definição de Escopo e Objetivos de Uso do website HomeOpera" e da norma ISO 9241:11. Este documento representava a demanda de informação que o grupo julgava necessária para que poder elaborar as especificações solicitadas pelo cliente.

Durante esta primeira etapa os líderes de equipe leram e solicitaram que todos os demais membros de suas equipes lessem a norma ISO9241:11 e o documento com a Definição de Escopo e de Objetivos de Uso do website HomeOpera. Propuseram através de discussão uma forma de repartição das atividades técnicas necessárias e sugeriram a forma de repartição pela estrutura do conteúdo (cada integrante do grupo realiza o trabalho referente a uma parte do documento de especificação que está sendo solicitado). Junto com a divisão de atividades, os líderes propuseram um cronograma detalhado para a tarefa.

Na primeira etapa desta atividade, cada líder deveria repartir e acompanhar a realização das metas dentro dos prazos propostos, cobrar e integrar os resultados e, finalmente revisar os documentos resultantes da atividade e os submeter a aprovação do grupo.

No dia 14/04 os líderes submeteram para a gerente de projetos do LabIUtil Empresa Virtual (Sra. Virgínia Leite), via e-mail, o documento com a estrutura da 
especificação, buscando negociar com ela a sua aprovação. Ocorreu neste momento, um atraso na execução da tarefa, devido a idas e vindas buscando acertar o documento, uma vez que alguns grupos apresentaram propostas de entrevista equivocadas.

Após as negociações com a gerente de projetos e da aprovação da estrutura da especificação, os lideres enviaram o documento ao responsável pelo projeto na empresacliente NeoGrid, Sr Vinícius Rodrigues Nunes, e solicitaram a ele os dados necessários para o preenchimento da especificação solicitada. A interação com o Sr. Vinicius foi realizada pelos líderes do grupo exclusivamente através do e-mail interno do TelEduc, com cópia para vinicius.nunes@ neogrid.com.br.

Obtidas as informações, o grupo elaborou o documento final de especificação de requisitos de usabilidade, completando a estrutura de especificação (conforme anexo $\mathrm{C}$ da norma ISO 9241:11). No dia 28/04, os líderes enviaram a versão final do documento para a $\mathrm{Sr}^{\mathrm{a}}$ Virgínia Leite.

No dia seguinte (29/04), o professor da disciplina encerrou oficialmente as atividades do "Estágio Virtual" agradecendo a participação de todos os alunos convidando-os a retornarem para as aulas presenciais em sala de aula.

\subsection{Conclusões sobre o Experimento}

Durante a realização do estudo de caso com o "Estágio Virtual" constatou-se a ocorrência de fatos e manifestações favoráveis e desfavoráveis face à realização da experiência piloto com o estágio virtual. Os fatos desfavoráveis foram interpretados pela equipe do Estágio Virtual como fonte de análise para as necessárias revisões na proposta e na definição de cuidados na sua implementação.

Portanto, os Aspectos Positivos que estão relacionados a aprendizagem da colaboração desenvolvida pelos alunos, professor e tutora, bem como, reforçam adequação da abordagem de Vygotsky a esta proposta, os Aspectos Gerais que permearam toda a realização do estudo, e, em especial, os Aspectos Específicos originados por incidentes ocorridos durante as atividades do experimento (problema, causa e solução/lição aprendida) serão descritos a seguir:

\subsubsection{Aspectos Positivos}

Os principais aspectos positivos foram à facilidade de organização entre os membros de algumas equipes para a execução das tarefas. Muitos estavam motivados e tiveram facilidade em colaborar; as iniciativas de colaboração provenientes dos alunos foram incentivadas pela tutora; interações com um profissional externo convidado. Em uma das etapas para a conclusão da atividade 2, houve interações entre os líderes de equipe e o Sr. Vinicius, participante real e externo, bem como, representante da empresa-cliente NeoGrid, que permitiram trocas sociais importantes para a aprendizagem do aluno e superação da dificuldade de realizar a leitura do hiperdocumento na tela do computador. Um aluno de um grupo encontrou uma solução para colaborar com os demais.

\subsubsection{Aspectos Gerais}

Durante o primeiro encontro presencial para a apresentação da proposta do "Estágio Virtual" a maioria dos alunos mostraram-se interessados e motivados para a realização do experimento. Porém, no decorrer do processo perceberam que não precisavam da EAD e que o compromisso e a responsabilidade com o estudo de caso 
eram bem maiores do que haviam pré-suposto. Os problemas de funcionamento e de usabilidade com as ferramentas do TelEduc (principalmente as de comunicação), as exigências de um curso baseado na abordagem sócio-interacionista (assumir uma postura colaborativa, mais tempo de dedicação, maior empenho nas atividades), uma turma geograficamente próxima e a ausência do computador na residência de alguns alunos, os levaram a questionar a validade da experiência e a solicitar o retorno das aulas presenciais.

Além dos aspectos do contexto dos alunos desfavorável a EAD, este fato se deve também ao número de tutores, que, durante o experimento, mostrou-se insuficiente para atender o número de alunos do curso. Isto acarretou problemas quanto ao tempo de resposta nas avaliações das atividades e para feedback das atividades intermediárias. Em função disso, os prazos para as realizações e entregas das tarefas ficaram prejudicados.

Assim, criou-se uma situação na qual as lideranças da turma se repartiram entre os que colaboravam com a experiência e os que eram contra ela.

\subsubsection{Aspectos Específicos}

São aqueles originados por incidentes ocorridos durante as atividades do experimento: (problema, causa e solução/lição aprendida), descritos na tabela 1 a seguir.

Tabela 1 - Relação dos Aspectos Específicos identificados durante a realização do estudo de caso com o "Estágio Virtual".

\begin{tabular}{|c|c|c|}
\hline \multicolumn{3}{|c|}{ ASPECTOS ESPECÍFICOS } \\
\hline Problema & Causa & Lição Aprendida \\
\hline Cronograma/Atividades & $\begin{array}{l}\text { Previsão errada do } \\
\text { cronograma (falta de tempo } \\
\text { para a realização do estágio) }\end{array}$ & $\begin{array}{l}\text { A realização do estágio requer } \\
\text { um tempo especial para permitir } \\
\text { que as interações entre pessoas } \\
\text { ocorram adequadamente }\end{array}$ \\
\hline $\begin{array}{l}\text { Falta da Ferramenta "Bate- } \\
\text { Papo" }\end{array}$ & $\begin{array}{l}\text { Avaliação equivocada da } \\
\text { repercussão da decisão de não } \\
\text { usar a ferramenta }\end{array}$ & $\begin{array}{l}\text { Discutir o uso desta ferramenta } \\
\text { com os alunos }\end{array}$ \\
\hline $\begin{array}{l}\text { Indicador da presença dos } \\
\text { colegas no TelEduc }\end{array}$ & $\begin{array}{l}\text { O TelEduc não dispunha deste } \\
\text { recurso }\end{array}$ & $\begin{array}{l}\text { A interação síncrona é } \\
\text { importante para agilizar } \\
\text { discussões e compartilhar idéias }\end{array}$ \\
\hline $\begin{array}{l}\text { Imagens na ferramenta } \\
\text { "Mural" }\end{array}$ & $\begin{array}{l}\text { Falta de conhecimento das } \\
\text { limitações da ferramenta }\end{array}$ & $\begin{array}{l}\text { Testar as possibilidades da } \\
\text { ferramenta antes de solicitar uma } \\
\text { atividade que a mesma não apóia }\end{array}$ \\
\hline $\begin{array}{l}\text { Ferramenta "Correio" } \\
\text { (grupos) }\end{array}$ & $\begin{array}{l}\text { Falta de testes com a } \\
\text { ferramenta, e falta de um } \\
\text { grupo e um aluno fictício para } \\
\text { testes }\end{array}$ & $\begin{array}{l}\text { Testar o ambiente de forma } \\
\text { abrangente; criar personagens de } \\
\text { testes para descobertas de } \\
\text { eventuais falhas }\end{array}$ \\
\hline $\begin{array}{l}\text { Usabilidade no TelEduc (* e } \\
\text { apont.) }\end{array}$ & $\begin{array}{l}\text { Características da interface } \\
\text { que limita a eficiência das } \\
\text { interações }\end{array}$ & $\begin{array}{l}\text { Critérios de usabilidade } \mathrm{p} / \mathrm{a} \\
\text { escolha do ambiente }\end{array}$ \\
\hline Usabilidade com o CMAPTool & $\begin{array}{l}\text { Problemas na interface e curto } \\
\text { prazo para a realização dos } \\
\text { mapas conceituais. }\end{array}$ & $\begin{array}{l}\text { Dar mais tempo para a } \\
\text { apropriação da ferramenta }\end{array}$ \\
\hline Download do CMAPTool & Aumento da carga de trabalho & $\begin{array}{l}\text { Evitar atividades desnecessárias } \\
\text { (verificar licença de uso do } \\
\text { CMAPTool) }\end{array}$ \\
\hline $\begin{array}{l}\text { Dúvidas de interpretação } \\
\text { Agenda } 1\end{array}$ & Falta de clareza no texto & $\begin{array}{l}\text { Ter um cuidado adicional na } \\
\text { redação de instruções ao alunos }\end{array}$ \\
\hline $\begin{array}{l}\text { Falta de Regras para } \\
\text { Ferramentas Comunicação } \\
\text { (Mural/Fórum) }\end{array}$ & $\begin{array}{l}\text { Problema na definição dos } \\
\text { papéis/objetivos das } \\
\text { ferramentas de comunicação }\end{array}$ & $\begin{array}{l}\text { Definir as funções para o uso das } \\
\text { ferramentas de comunicação e } \\
\text { eleger uma oficial para a } \\
\text { comunicação com os tutores }\end{array}$ \\
\hline
\end{tabular}




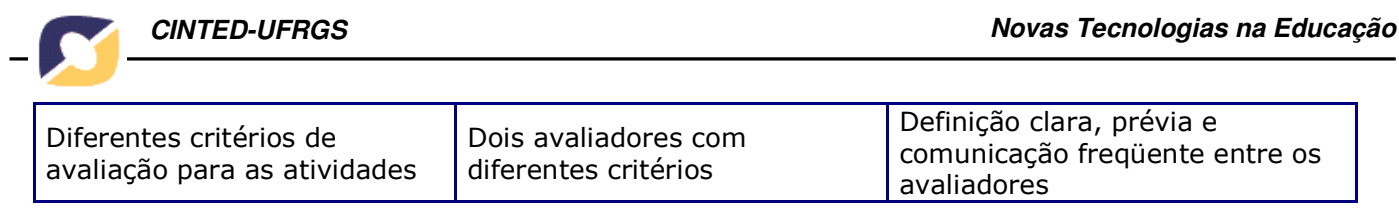

\section{CONCLUSÕES}

Este trabalho propôs uma abordagem diferenciada para a disciplina de Engenharia de Usabilidade do curso de Sistemas de Informação da UFSC. O "Estágio Virtual" apresenta-se como uma alternativa de ensino-aprendizagem mais participativa, comprometida e contextualizada, contrapondo-se a uma tendência instrucionista encontrada em diversas iniciativas de cursos via Internet.

O estudo de caso demonstrou a viabilidade desta proposta e possibilitou identificar as vantagens, os problemas ocorridos e suas causas, bem como, as providencias a serem tomadas para que estes problemas não se repitam.

A abordagem sócio-interacionista de Vygotsky orientou o desenvolvimento da proposta. Considera-se que a adoção desta abordagem busca contextualizar as atividades de aprendizagem, atendendo os requisitos da ementa da disciplina, através da proposição de problemas reais. Ou seja, esta abordagem é que permite a íntima relação entre o conteúdo da disciplina e os problemas no dia a dia da empresa.

As ferramentas de comunicação presentes no ambiente virtual de aprendizagem TelEduc, possibilitaram a mediação dos processos de aprendizagem apoiando a comunicação e as trocas de experiência entre os alunos, dos alunos com os personagens fictícios da empresa virtual e dos alunos com a tutora e professor da disciplina.

Acredita-se que a proposta de Estágio Virtual apresentada neste trabalho possa ser aplicada em diversos domínios, e certamente ser adaptada a partir das necessidades e objetivos específicos de cada domínio. O principal aspecto inovador introduzido com esta proposta é a idéia de contextualizar a aprendizagem do aluno a partir dos problemas e necessidades de uma empresa virtual e fictícia. Em outros domínios, talvez não seja exatamente uma "Empresa Virtual" e sim um "laboratório virtual", ou então um "tribunal virtual", porém, o que deve ser mantido é a busca da aproximação entre a teoria e atividades práticas de aprendizagem (problemas reais no cotidiano de uma empresa).

Um outro aspecto a ser salientado é que a proposta permite que os alunos realizem estágio em áreas onde normalmente é pequena a demanda por estagiários. Um exemplo bem típico é o da própria Engenharia de Usabilidade abordado neste trabalho. Através desta proposta é possível criar situações que possam melhorar a formação do aluno e com isso proporcionar maior qualidade ao processo de ensino-aprendizagem.

Acredita-se que a realização deste trabalho contribuiu para a busca de alternativas que acrescentem qualidade aos processos de ensino-aprendizagem aproximando a teoria da prática, e tornando o ambiente de estudo mais interativo, participativo e interessante. As lições aprendidas a partir dos problemas identificados também contribuíram, pois permitiram a proposição de melhorias. A perspectiva de realização de novos experimentos com esta proposta é a principal motivação para a continuidade deste trabalho.

\section{REFERÊNCIAS BIBLIOGRÁFICAS}

FUKS, HUGO. Aprendizagem e Trabalho Cooperativo no Ambiente Aulanet. Revista brasileira de Informática na Educação.Florianópolis, 2000. pp. 53-73. 
LIMA, LARISSA S. D., Proposta de um Framework de Apoio ao Desenvolvimento de Cursos a Distância baseados na Abordagem Sócio-Histórica de Vigotsky. Florianópolis: UFSC, 2002. (Dissertação de Mestrado)

LUCENA, CARLOS; FUKS, HUGO. Professores e Aprendizes na Web: a Educação na Era da Internet. Edição e organização: Nilton Santos. Rio de Janeiro: Clube do futuro, 2000 .

MAYHEW, DEBORAH J. The Usability Engeneering Lifecicle: A Practioner's Handbook for User Interface Design. Morgan Kaufmann Publishers, 1999 p.560.

NISKIER, ARNALDO. Educação à Distância - A tecnologia da esperança. Edições Loyola, $2^{a}$ ed. São Paulo, Brasil, 2000.

PÁDUA, CLARINDO I.P.S; RIBEIRO, ALOÍSIO A. JÚNIOR. Usabilidade a Baixo Custo. Departamento de Ciência da Computação da UFMG. Disponível em: $<$ http://www.dcc.ufmg.br/ clarindo/pesquisa/gestus/artigousabbaixocusto.pdf> Acesso em: 14 de ago. 2003.

REGO, TERESA C. Vygotsky: Uma Perspectiva Histórico-Cultural da Educação. Editora Vozes, $8^{a}$ edição, 1999

SILVA, MARCO. Criar e professorar um curso online: relato de experiência. In Educação Online.Edições Loyola, São Paulo. 2003.

TELEDUC, Ambiente de suporte para ensino-aprendizagem à distância. Disponível em: $<$ http://teleduc.nied.unicamp.br/ teleduc/pagina_inicial/index.php $>$. Acesso: 25 ago 2003.

VAVASSORI, FABIANE B; RAABE, ANDRÉ L. A. Organização de atividades de aprendizagem utilizando ambientes virtuais: um estudo de caso. In Educação Online. Edições Loyola. São Paulo, 2003.

VICCARI, ROSA M.; ALMEIDA, ADJA F. Construindo Um Ambiente de Aprendizagem à Distância Inspirado na Concepção Sócio-Interacionista de Vygotsky. In Educação Online. Edições Loyola. São Paulo, 2003. 